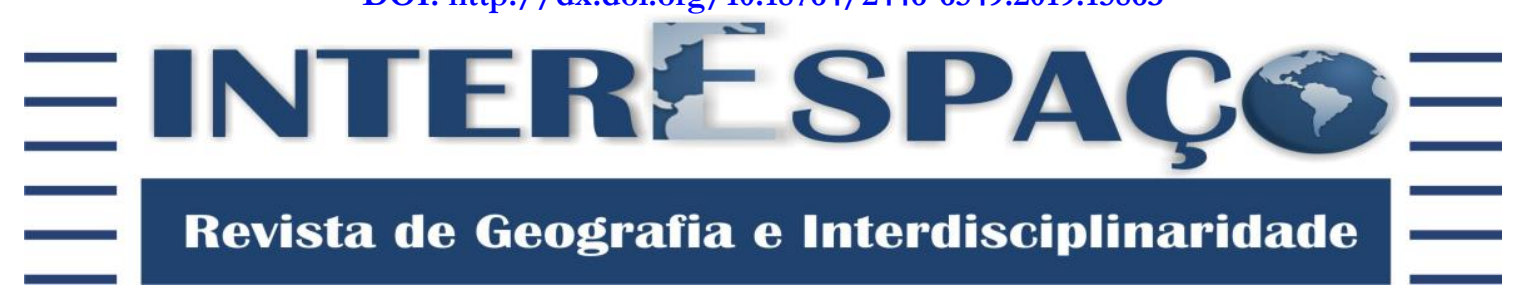

\title{
HIDRELÉTRICA BELO MONTE: estudo da desterritorialização das famílias da Comunidade Babaquara - Altamira/PA
}

\author{
BELO MONTE HYDROELECTRIC: study of deterritorialization of families in \\ the Babaquara Community - Altamira/PA
}

\section{HIDROELÉCTRICA BELO MONTE: estudio de la desterritorialización de familias en la Comunidad Babaquara - Altamira/PA}

\author{
Darlene Costa da Silva \\ Doutora em Geografia pela Universidade Federal de Rondônia - UNIR. \\ darlene-silva1@hotmail.com / http://orcid.org/0000-0001-5345-7117 \\ Maria Madalena de Aguiar Cavalcante \\ Doutora em Geografia pela Universidade do Paraná - UFPR. Professora da Universidade Federal \\ de Rondônia - UNIR. \\ mada.geoplan@gmail.com / http://orcid.org/0000-0001-8323-4280
}

Recebido para avaliação em 01/07/2019; Aceito para publicação em 18/08/2019.

\begin{abstract}
RESUMO
A territorialização da hidrelétrica de Belo Monte provocou profundas transformações no modo de vida da população da comunidade Babaquara. Entretanto, constata-se que, contraditoriamente, apesar da mudança, há uma resistência em permanecer nas margens direita do rio Xingu, onde metade do seu território foi inundado pela água do reservatório. Sendo assim, tem-se no escopo deste artigo o intuito de analisar as transformações ocorridas na comunidade Babaquara a partir da territorialização da Hidrelétrica Belo Monte, identificando as transformações no modo de vida desta população. Os resultados apresentados foram coletados entre novembro de 2014 e novembro de 2016, período no qual foram entrevistadas 12 familias, com visitas sistematizadas à comunidade e vivência junto às famílias que foram indenizadas pelo processo de compensação das condicionantes atribuídas ao Consórcio Construtor. Para atualização dos dados, uma nova expedição foi organizada em junho 2020. Além disso, foi realizada revisão de literatura para definição do recorte teóricometodológico que considere a realidade de pesquisa. Tal circunstância tem modificado o modo de vida, o trabalho, a produção de alimentos e as relações sociais da população. As transformações socioeconômicas e ambientais trazem em sua gênese conflitos sociais e culturais em razão da sobreposição de grupos econômicos exógenos com interesses destoantes aos percebidos nas populações locais. Deste modo, parte-se da premissa que as transformações socioambientais transcendem os aspectos sociais, produtivos e econômicos, afetando a relação das famílias com o ambiente. Historicamente, as famílias estabeleceram relação com o rio, praticando a pesca, com a floresta, se beneficiando dos recursos naturais para desenvolver atividades de extrativismo, a produção de farinha, hortas e frutas nativas nos quintais às margens do rio Xingu.
\end{abstract}

Palavras-chave: Belo Monte; População Tradicional; Modo de Vida; Babaquara.

\begin{abstract}
The territorialization of the Belo Monte hydroelectric plant caused profound changes in the way of life of the population of the Babaquara community. However, it appears that, contradictorily, despite the change, there is a resistance to remain on the right banks of the Xingu River, where half of its territory was flooded by water from the reservoir. Therefore, the scope of this article aims to
\end{abstract}


| Hidrelétrica Belo Monte: estudo da desterritorialização das famílias da Comunidade Babaquara Altamira/PA|

\section{|Darlene Costa Silva | Maria Madalena de Aguiar Cavalcante |}

analyze the changes that have occurred in the Babaquara community from the territorialization of the Belo Monte Hydroelectric Plant, identifying the changes in the lifestyle of this population. The results presented were collected between November 2014 and November 2016, during which 12 families were interviewed, with systematic visits to the community and experience with the families who were compensated for the process of compensating the conditions attributed to the Construtor Consortium. In order to update the data, a new expedition was organized in June 2020. In addition, a literature review was carried out to define the theoretical-methodological framework that considers the research reality. This circumstance has changed the way of life, work, food production and the social relationships of the population. Socioeconomic and environmental changes bring about social and cultural conflicts due to the overlapping of exogenous economic groups with interests that differ from those perceived by local populations. In this way, it is based on the premise that socio-environmental transformations transcend social, productive and economic aspects, affecting the relationship of families with the environment. Historically, families have established a relationship with the river, practicing fishing, with the forest, benefiting from natural resources to develop extractive activities, the production of flour, vegetable gardens and native fruits in backyards on the Xingu River.

Keywords: Belo Monte; Traditional Population; Lifestyle; Babaquara.

\section{RESUMEN}

La territorialización de la central hidroeléctrica de Belo Monte provocó profundos cambios en la forma de vida de la población de la comunidad de Babaquara. Sin embargo, parece que, contradictoriamente, a pesar del cambio, existe una resistencia a permanecer en la margen derecha del río Xingú, donde la mitad de su territorio fue inundado por el agua del embalse. Por tanto, el alcance de este artículo tiene como objetivo analizar los cambios que se han producido en la comunidad de Babaquara a partir de la territorialización de la Central Hidroeléctrica de Belo Monte, identificando los cambios en el estilo de vida de esta población. Los resultados presentados fueron recolectados entre noviembre de 2014 y noviembre de 2016, durante los cuales se entrevistaron a 12 familias, con visitas sistemáticas a la comunidad y experiencia con las familias que fueron compensadas por el proceso de compensación de las condiciones atribuidas al Consorcio Constructor. Con el fin de actualizar los datos, se organizó una nueva expedición en junio de 2020. Además, se realizó una revisión de la literatura para definir el marco teórico-metodológico que considera la realidad de la investigación. Esta circunstancia ha cambiado la forma de vida, el trabajo, la producción de alimentos y las relaciones sociales de la población. Los cambios socioeconómicos y ambientales generan conflictos sociales y culturales debido a la superposición de grupos económicos exógenos con intereses diferentes a los percibidos por las poblaciones locales. De esta manera, se parte de la premisa de que las transformaciones socioambientales trascienden los aspectos sociales, productivos y económicos, afectando la relación de las familias con el medio ambiente. Históricamente, las familias han establecido una relación con el río, practicando la pesca, con el bosque beneficiándose de los recursos naturales para desarrollar actividades extractivas, la producción de harina, huertas y frutos nativos en los patios.

Palabras clave: Belo Monte; Población Tradicional; Modo de Vida; Babaquara.

\section{INTRODUÇÃO}

A desterritorialização de comunidades tradicionais com a construção de

hidrelétricas está sendo recorrente na Amazônia. Neste contexto encontra-se a Comunidade Babaquara, que faz parte do Projeto de Assentamento da Gleba Assurini, localizado no município de Altamira, sudoeste do estado do Pará. A desterritorialização “é 


\section{|Darlene Costa Silva | Maria Madalena de Aguiar Cavalcante |}

tratada como uma das marcas fundamentais de nosso tempo" (HAESBAERT, 2003, p. 113).

A Comunidade Babaquara possui duas formas de ocupação que determinam seu modo de vida. "O modo de vida se define pela forma como os moradores percebem, vivem e concebem, em específico, o espaço” (SUZUKI, 1996, p. 179).

O primeiro acesso à comunidade se deu por via hídrica, com dinâmica e relações culturais, estabelecidas estritamente com o rio Xingu. A outra área, definida como de terra firme, possui sua dinâmica influenciada pela lógica da estrada, possibilitando relações distintas no que tange o uso dos recursos naturais e a meta de produção em relação ao núcleo da comunidade, às margens do Xingu.

No que diz respeito à Comunidade Babaquara foram feitas entrevistas com 12 famílias, total de vinte lotes que compõem o núcleo à margem direita do Reservatório do Xingu, na Área de Influência Direta (AID). Essas famílias são constituídas em média por quatro (04) membros e, em sua maioria, de origem nordestina. Os moradores entrevistados possuem entre 38 (trinta e oito) e 15 (quinze) anos de residência na comunidade. Uma nova expedição foi realizada em junho de 2020 para atualização dos dados, sendo revisitadas as famílias que permaneceram na comunidade após o enchimento do lago. No mapa 01 destaca-se a localização da comunidade, de modo que se pode perceber a ligação tanto com rio quanto com a estrada de acesso. 
| Darlene Costa Silva | Maria Madalena de Aguiar Cavalcante |

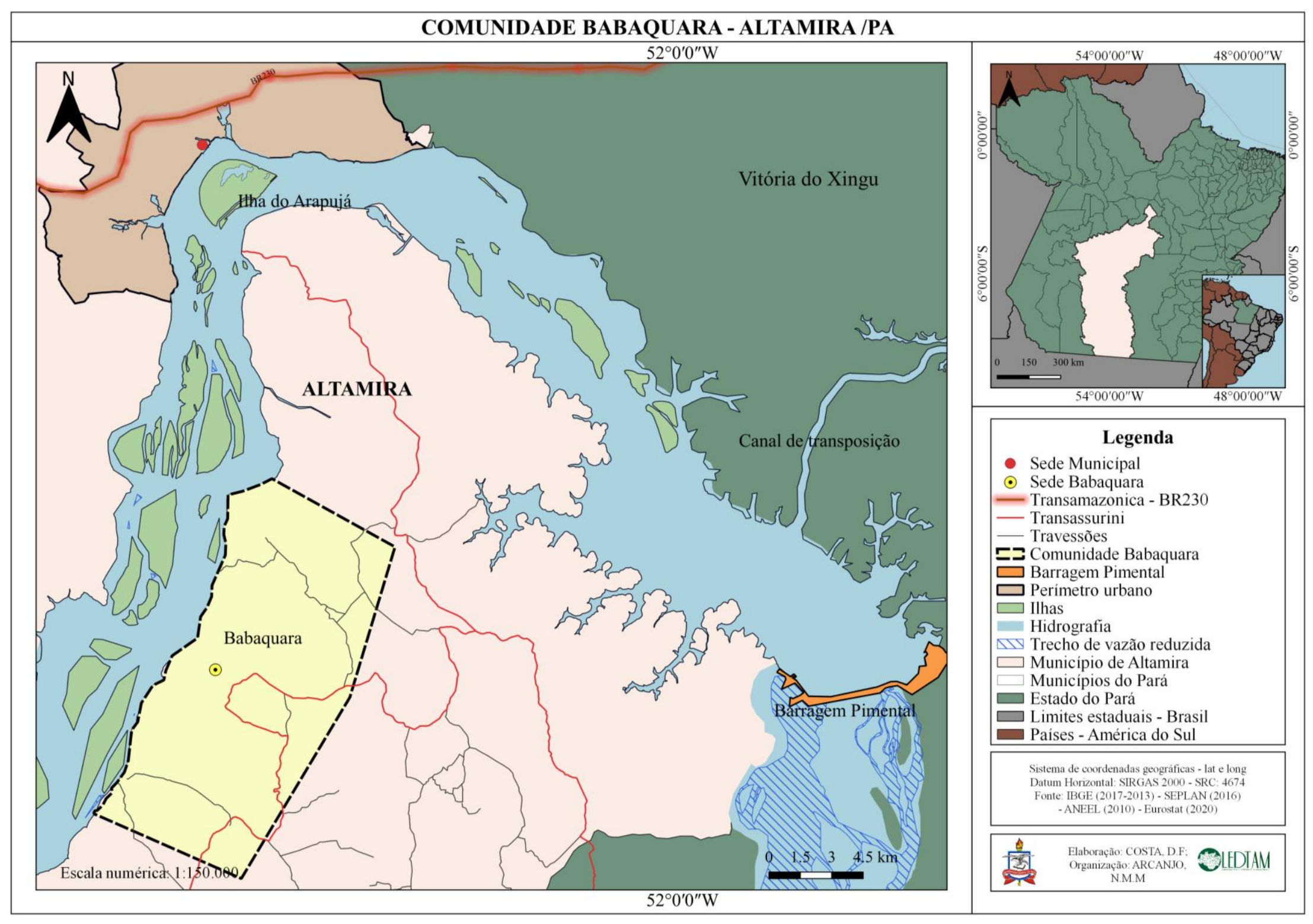

\begin{tabular}{|c|c|c|c|c|c|}
\hline InterEspaço & Grajaú/MA & v. 5, n. 18 & p. $01-11$ & set./dez. 2019 & Página 4 \\
\hline
\end{tabular}


| Hidrelétrica Belo Monte: estudo da desterritorialização das famílias da Comunidade Babaquara Altamira/PA|

|Darlene Costa Silva | Maria Madalena de Aguiar Cavalcante |

Todas as famílias foram indenizadas por parte da propriedade que estava na cota 100, tendo indenização com valores variados oscilando entre 14 mil a 95 mil reais, e em 2020 permaneceram somente oito famílias. O artigo tem-se no escopo o intuito de analisar as transformações ocorridas na comunidade Babaquara a partir da territorialização da hidrelétrica Belo Monte.

A comunidade passou por um processo de desterritorialização de forma parcial, atingindo somente as bordas das propriedades às margens do rio. Conforme Haesbaert (2002, 2003, 2009), a desterritorialização tem sido centro de discussões na última década. O mundo vive atualmente um de seus períodos mais contraditórios e complexos, com os efeitos da modernização que impõem novas geometrias aos espaços.

\section{A DESTERRITORIALIZAÇÃO DA COMUNIDADE BABAQUARA}

O território pode se desterritorializar, isto é, abrir-se, engajar-se em linhas de fuga e até sair do seu curso e se destruir. A espécie humana está mergulhada num imenso movimento de desterritorialização, no sentido de que seus territórios "originais" se desfazem ininterruptamente com a divisão social do trabalho, com a ação dos deuses universais que ultrapassam os quadros da tribo e da etnia, com os sistemas maquínicos que a levam a atravessar, cada vez mais rapidamente, as estratificações materiais e mentais (GUATTARI; RONILK, 2010, p. 388).

A comunidade está à margem direita do Trecho do Reservatório do Rio Xingu, sendo assim denominada pelo RIMA (2009) como Área de Influência Direta.

Conforme o EIA/RIMA (2009), a comunidade Babaquara está situada na Subárea 5 do Reservatório do Xingu Margem Direita. A Subárea Rural 5, denominada Reservatório do Xingu Margem Direita, compreende o restante da área do município de Altamira, na conhecida região da Rodovia Transassurini (ou região do Assurini), relacionando-se com o compartimento do Aproveitamento Hidrelétrico (AHE) de Belo Monte do Reservatório da Xingu na margem direita.

Assim como a Subárea Reservatório do Xingu Margem Esquerda, a Subárea 5 é uma das mais importantes da AID, em função de sua situação relativa a um dos principais compartimentos do empreendimento - o Reservatório do Xingu - e ao principal elemento do (AHE) Belo Monte, a barragem. É importante destacar, ainda, sua proximidade e relação de dependência com a cidade de Altamira, polo regional e principal referência para toda a população da região (EIA/RIMA, 2009, p. 426, v. 22). 
| Hidrelétrica Belo Monte: estudo da desterritorialização das famílias da Comunidade Babaquara Altamira/PA|

\section{|Darlene Costa Silva | Maria Madalena de Aguiar Cavalcante |}

Na Figura 1, destaque para a zona Rural e demais Núcleos de Referência Rural. Compõem este item os demais núcleos de referência rural identificados na Subárea 5 da AID, que são os seguintes: Babaquara, Itapuama, Mangueiras, Transassurini, Travessão do Cajá, Travessão do Paratizinho, Travessão do Espelho, Bom Jardim I (Assurini), Travessão Pimentel (Quatro Bocas) e Ramal dos Crentes (EIA/RIMA, 2009, p. 259, v. 22).

Figura 1 - Subárea 5: Reservatório do Xingu Margem Direita

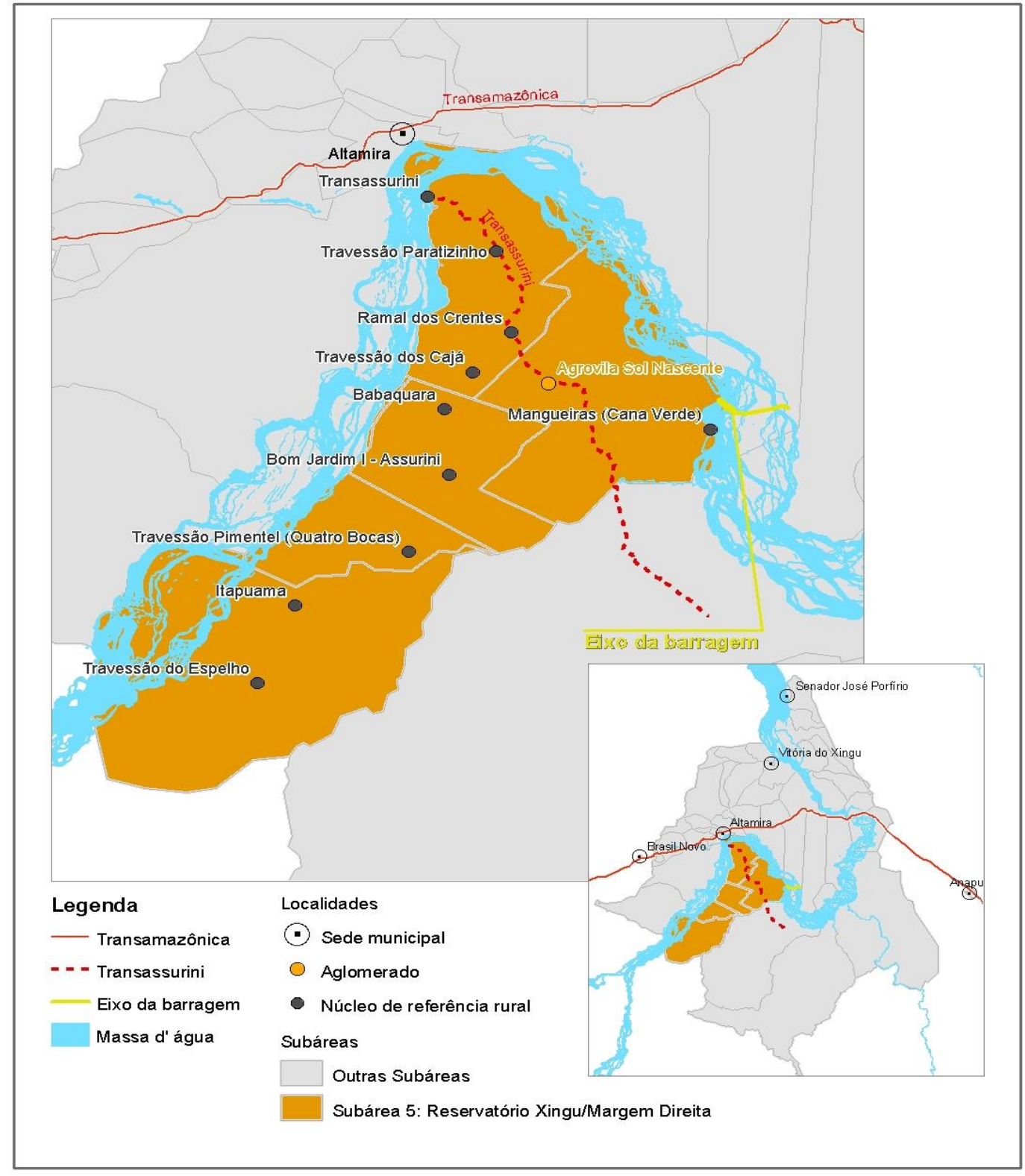

Fonte: Leme Engenharia, 2007/2008. EIA, 2009, p. 259, v. 22.

O processo de desterritorialização pode ser tanto simbólico, com a destruição de símbolos, marcos históricos, identidades, quanto concreto, material - político e/ou econômico, pela destruição de antigos laços/fronteiras econômico-políticos de integração. 
| Hidrelétrica Belo Monte: estudo da desterritorialização das famílias da Comunidade Babaquara Altamira/PA|

|Darlene Costa Silva | Maria Madalena de Aguiar Cavalcante |

Os indivíduos, classes e grupos sociais incorporam sempre, embora em diferentes níveis e escalas, perspectivas desterritorializadas/desterritorializantes (HAESBAERT, 2003, p. 181).

As mazelas que ficam após a construção de uma hidrelétrica deixam marcas profundas na vida dos moradores que resolveram permanecer na comunidade. Há propriedades com placas de venda (A, B), fato que em 2011 não era encontrado e os motivos são variados, como o medo da propriedade alagar pelo fato de o lote ser banhado pelos igarapés Babaquara ou Conradinho, que fica nas proximidades; por não poder plantar suas roças; pela busca de trabalho no Consórcio Belo Monte.

Algumas famílias passaram pelo processo de desterriteritorialização tanto na área rural quanto urbana, onde tinham suas casas nos bairros e foram remanejados para os Reassentamentos Urbanos Coletivos (RUC's), e receberam indenização por parte do lote na área rural que estava na cota 100.

Diante das dificuldades, várias famílias resolveram mudar para Altamira depois, para procurar oferta de emprego no Consórcio Belo Monte, resultando no abandono do lote $(\mathrm{C})$. Os novos proprietários são pessoas que moram em Altamira, adquiriram os lotes para plantar cacau, capim ou transformar em área de lazer.

Figura 2 - Marcas da Hidrelétrica Belo Monte
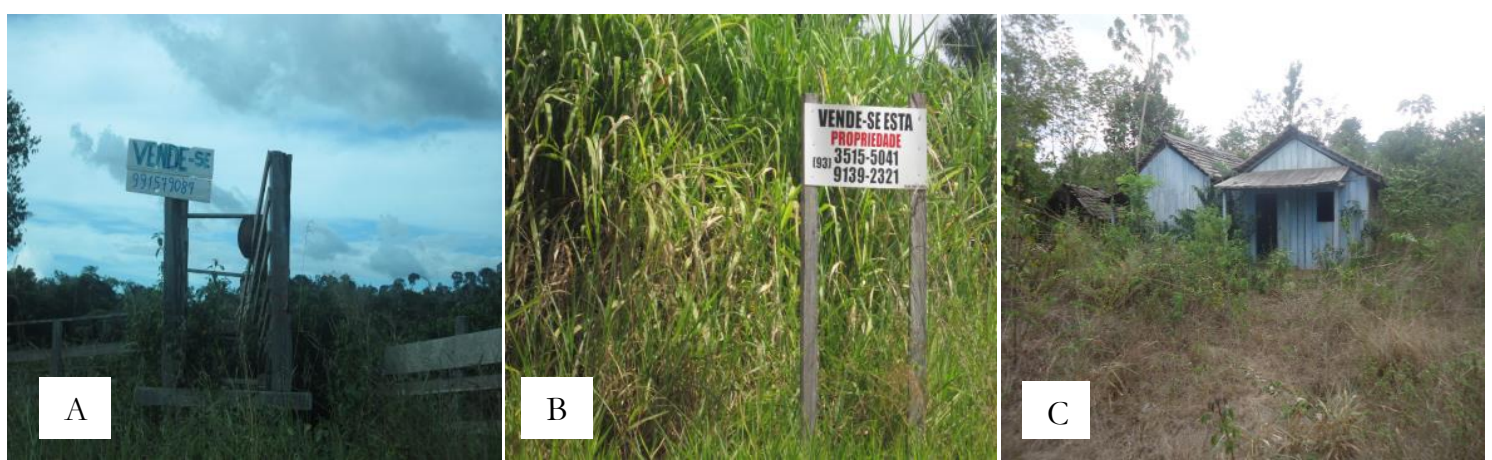

Fonte: Pesquisa de campo, 2016.

O cenário agora é a concentração de uma grande quantidade de terra nas mãos de uma única pessoa, tornando a propriedade em uma fazenda ou aumentando o seu cultivo de cacau. Famílias que antes moravam nas ilhas, receberam indenização e compraram a parte do lote de um parente ou amigo para ali recomeçar a vida. Um morador expressa sua insatisfação de como tudo se encontra na comunidade:

Antes as famílias eram organizadas, preocupadas com o futuro da comunidade, no decorrer do tempo principalmente com a chegada da hidrelétrica houve uma grande mudança: algumas foram embora para Altamira em busca de emprego, deixando tudo abandonado. Os que ficaram, quando convocamos para nos 
| Hidrelétrica Belo Monte: estudo da desterritorialização das famílias da Comunidade Babaquara Altamira/PA|

\title{
|Darlene Costa Silva | Maria Madalena de Aguiar Cavalcante |
}

reunir, para buscarmos melhorias, eles logo reclamam, dizendo que não vão perder tempo com isso, quem tem que fazer é o gestor municipal. Aí fica difícil lutar quase sozinho (Entrevistado 1, 2016).

As mazelas da hidrelétrica Belo Monte são inúmeras, tanto nas margens do rio como na terra firme. As pessoas que residiam às margens do rio receberam visitas dos representantes da Norte Energia em 2011, para identificação da área, vistoria da benfeitoria, marco e piquete nas propriedades.

Os moradores foram comunicados que seriam indenizados e deveriam deixar o lote. Essa definição perdurou por três anos e que eles não deveriam mais plantar, pois o que fizesse depois do cadastro não seria pago. Em depoimento, o morador relata:

\begin{abstract}
A Norte Energia já fez o levantamento da propriedade e colocou a placa. E recomendou a partir de agora o que vocês plantarem é de responsabilidade própria, não receberão mais nada por isso. Com a barragem, não vem o desenvolvimento, vamos perder as nossas coisas, nosso lazer, pois foi onde implantaram a pedra e o limite da água. E o rio vai ficar como se estivesse sempre no inverno, vamos ficar na pior. Belo Monte retrata o medo de perder a terra e não ser indenizados (Entrevistado 2, 2016).
\end{abstract}

Tal circunstância faz com que os agricultores passem por momentos de vulnerabilidade, uma vez que por três ciclos agrícolas deixam de organizar suas produções. Como consequência tem-se deslocamentos para a cidade, dependente de aposentadoria e benefícios. No final de 2014, as famílias receberam novamente representantes da Norte Energia com um novo discurso, dessa vez que seria indenizada somente a parte do lote que fica alagada no período chuvoso, referente à cota 100, pelo restante não seria pago nada, e que eles poderiam ficar e voltar às suas atividades normais. O morador desabafa:

\footnotetext{
Quem mexe com a terra, não sabe viver sem ela. Se hoje com o inverno a água mata todas as plantações, imagina com essa barragem, tudo vai desaparecer. Dessa forma, os moradores hoje se encontram sem perspectivas, pois ficam imaginando como vai ser a vida depois do término da barragem e o aumento do volume de água (Entrevistado 3, 2016).
}

O enchimento do lago tem marcado a trajetória de vida desta população com inúmeras transformações, sobretudo pela perda de seus meios de produção, do seu local de residência, sendo obrigada a adaptar-se às mudanças, principalmente relacionadas ao uso do rio.

\section{AQUI AINDA É O MEU LUGAR?}


| Hidrelétrica Belo Monte: estudo da desterritorialização das famílias da Comunidade Babaquara Altamira/PA|

|Darlene Costa Silva | Maria Madalena de Aguiar Cavalcante |

A Comunidade Babaquara faz parte do Projeto de Assentamento (PA) da Gleba Assurini, localizada no município de Altamira, sudoeste do estado do Pará. Sua formação espacial é produto da colonização da região como resultado do contexto político e econômico brasileiro da década de 1970.

A comunidade pertence ao projeto de assentamento criado através da Portaria INCRA-SR 01 no 51 de 17 de julho de 1995, que faz parte do PA Assurini, possui uma área de 32.000 hectares e previa a criação de 300 unidades familiares.

No Gráfico 01, nota-se a formação da comunidade a cada década, sendo ocupada e assim observa-se o crescimento demográfico de sua população até o início da construção da hidrelétrica.

Gráfico 01 - Crescimento populacional da comunidade ao longo as décadas.

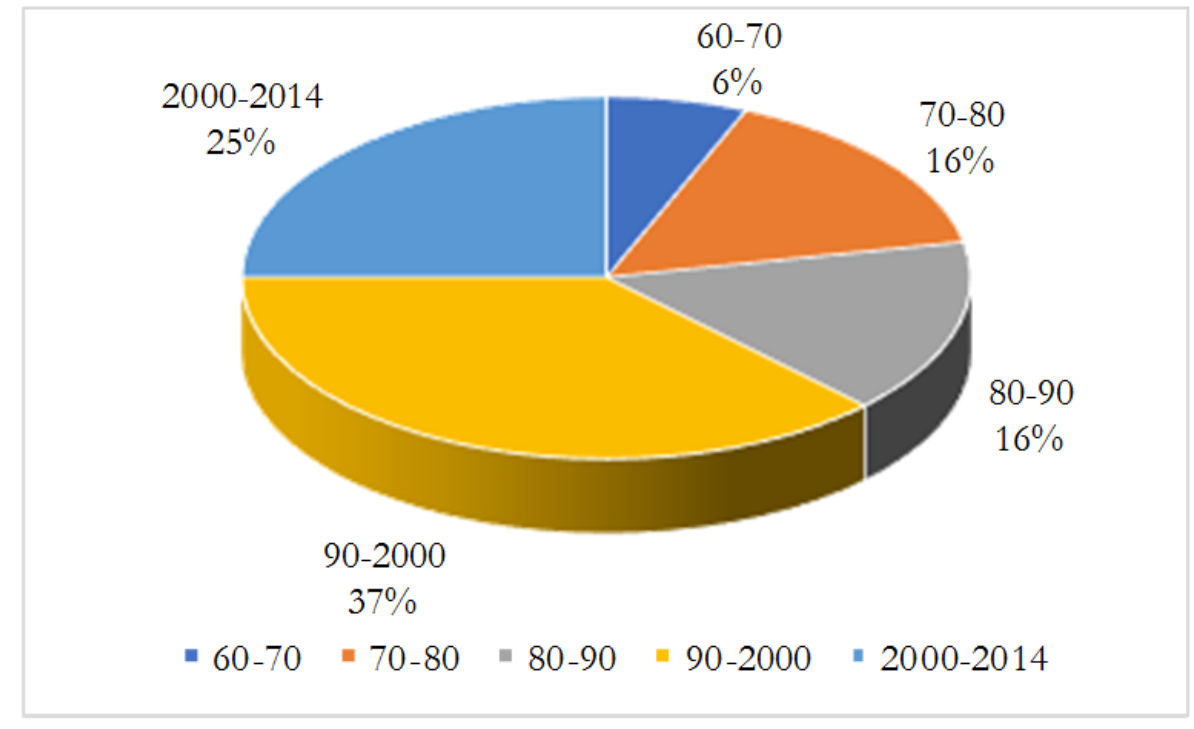

Fonte: Levantamento de campo, 2019.

A dinâmica de ocupação da região se repete na formação da Comunidade Babaquara, que inicialmente ocorreu às margens do rio Xingu e, com o aumento da demanda por terra, adentrou-se pela mata para estabelecer novos lotes. Importante destacar que esse processo de busca de novas áreas no interior da floresta também foi determinado pela dinâmica dos rios, uma vez que as famílias foram orientadas pelo fluxo dos igarapés Babaquara e Conradinho.

No que se refere a equipamentos, a comunidade dispõe dos serviços essenciais extremamente reduzidos. Dispõe de uma escola (A), posto de saúde (B), casa (C) e igreja (D); a comunidade tem outros espaços que marca a identidade de lugar, como: o campo de futebol, alguns bares e o rio Xingu com suas belas praias. Como podemos observar na sessão de fotos 03 a parte estrutural construída pelos moradores. 
| Hidrelétrica Belo Monte: estudo da desterritorialização das famílias da Comunidade Babaquara Altamira/PA|

|Darlene Costa Silva | Maria Madalena de Aguiar Cavalcante |

Figura 3 - Infraestrutura da comunidade

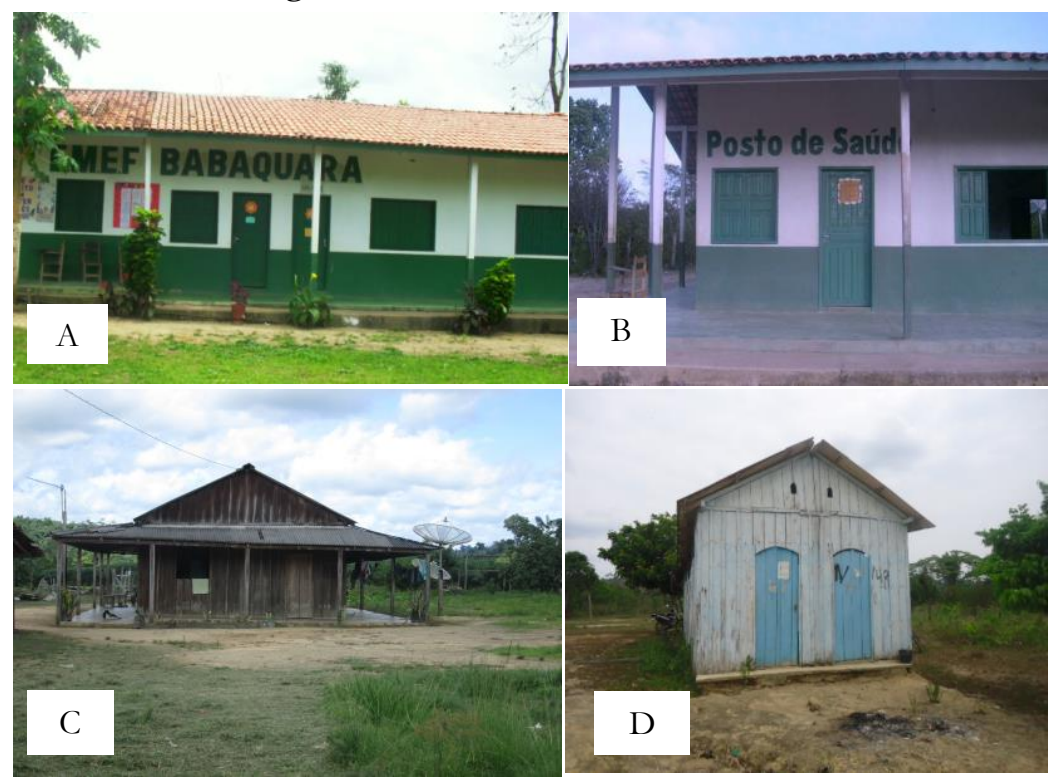

Fonte: Pesquisa de campo, 2016.

Nesse contexto, complementa Saquet sobre os territórios e as territorialidades:

[...] são vividos, percebidos e compreendidos de formas distintas; são substantivados por relações. Homogeneidades e heterogeneidades, integração e conflito, localização e movimento, identidades, línguas e religiões, mercadorias, instituições, natureza exterior ao homem; por diversidade e unidade; (i)materialidade (SAQUET, 2010, p. 25).

A Comunidade Babaquara ainda é o destino de muitos migrantes. Destino sim, pois, para alguns desses moradores, a migração ainda não terminou, inclusive, passou a ser lugar de abrigos para famílias impactadas pelo empreendimento em outras comunidades. Não tem sido fácil entender os desafios gerados em função da UHE Belo Monte, mas é circunstancial reconstruir a forma de uso da terra, das atividades desenvolvidas no rio, seus costumes vivenciados acerca dos modos de vida e do uso do espaço pelos atores sociais do território.

Os migrantes ao chegarem à comunidade já tinham objetivos definidos, uns vieram em busca de tranquilidade, outros admitiram ser a realização de um antigo sonho, ser proprietário de um "pedaço de terra", como mencionado no trabalho de Silva (2018, p. 120).

HIDRELÉTRICA BELO MONTE E A TRNASFORMAÇÃO NO MODO DE VIDA DA POPULAÇÃO AFETADA NA COMUNIDADE BABAQUARA 
| Hidrelétrica Belo Monte: estudo da desterritorialização das famílias da Comunidade Babaquara Altamira/PA|

|Darlene Costa Silva | Maria Madalena de Aguiar Cavalcante |

A vida dos homens em comunidade é uma busca pela garantia do convívio pautado nas relações proximais que permitam aos indivíduos a sua inserção na coletividade. A comunidade é para Tedesco (1999) uma integração fundamental para a estrutura do conjunto social e para o desenvolvimento do homem; ela tende a promover a consciência em relação aos outros. É uma forma de manter o funcionamento da estrutura social por meio do reconhecimento do outro em detrimento da individualidade.

A estrutura da Hidrelétrica Belo Monte (Figura 04) significou um verdadeiro retrocesso quando se considera a perda de laços sociais concretos e subjetivos os quais foram construídos ao longo dos anos por estas populações.

A barragem principal no Rio Xingu está localizada a $40 \mathrm{~km}$ a montante da cidade de Altamira, no Sítio Pimental, formando o Reservatório do Xingu. A partir deste reservatório, parte da água seria desviada por um canal de derivação de $20 \mathrm{~km}$ de comprimento e $200 \mathrm{~m}$ de largura para um reservatório intermediário, localizado a aproximadamente $50 \mathrm{~km}$ de Altamira, na região cercada pela Volta Grande do Xingu.

A área dos reservatórios é de $516 \mathrm{~km}^{2}$, dividida entre os municípios de Vitória do Xingu $\left(248 \mathrm{~km}^{2}\right)$, Brasil Novo $\left(0,5 \mathrm{~km}^{2}\right)$ e Altamira $\left(267 \mathrm{~km}^{2}\right)$.

Figura 04 - Estrutura da Hidrelétrica Belo Monte

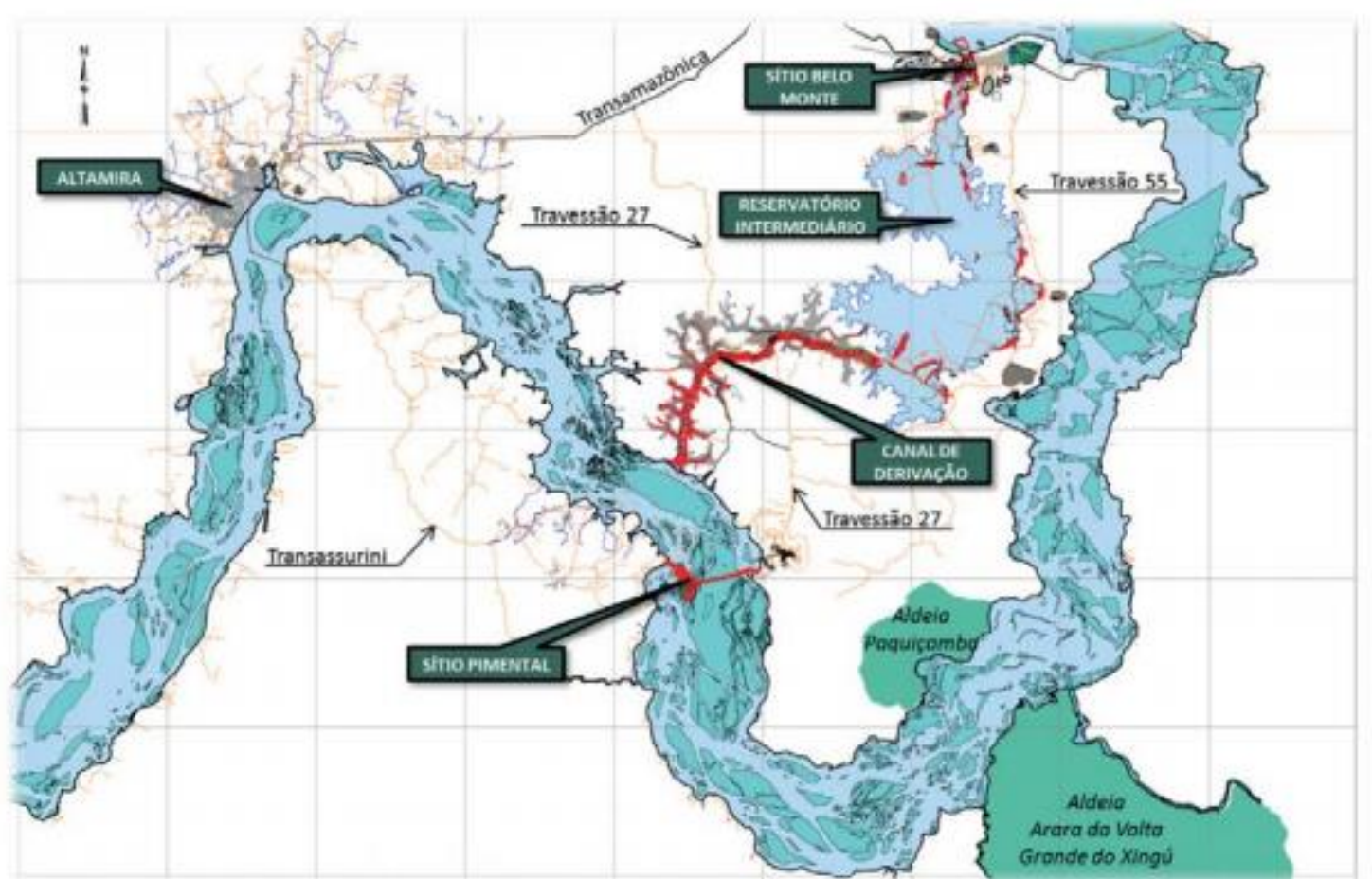

Fonte: http://cbdb.rarolabs.com.br/system/uploads/revista/documento/4/RevBrasEngBarragensMaio2017.

Para Santos (1994), o lugar abarca uma permanente mudança, decorrente da própria lógica da sociedade e das inovações técnicas que estão sempre transformando o espaço geográfico. 
| Hidrelétrica Belo Monte: estudo da desterritorialização das famílias da Comunidade Babaquara Altamira/PA|

\section{|Darlene Costa Silva | Maria Madalena de Aguiar Cavalcante |}

A compreensão do lugar no movimento das contradições exige entendê-lo pautado nos seus pares dialéticos: o interno e o externo; o novo e o velho; o local e o global. O interno abarca as variáveis que estão presentes no lugar, aquilo que aparece como local; e o externo constitui-se no que está fora do lugar e se apresenta em uma escala de ação maior. Contudo, os lugares têm variáveis internas e externas, sendo que o externo, ao se inserir no lugar, se internaliza. De acordo com Santos (1994), a concepção de lugar está intimamente relacionada à própria definição de espaço:

\footnotetext{
Tudo que existe num lugar está em relação com os outros elementos desse lugar. O que define o lugar é exatamente uma teia de objetos e ações com causa e efeito, que forma um contexto e atinge todas as variáveis já existentes, internas; e as novas, que se vão internalizar (SANTOS, 1994, p. 97).
}

Além disso, existem bens materiais e imateriais que representam valores simbólicos que dinheiro nenhum pagará. Os laços de parentesco, compadrio e amizade foram fragmentados, distanciados e enfraquecidos, no decorrer do processo de espera pelo desfecho que a Norte Energia iria dar a cada família.

O exemplo mais forte e lamentado foi a perda da estreita e cotidiana relação com o Rio Xingu. A identidade do lugar tem relação com o espírito deste, cujo enraizamento e o sentimento de familiaridade dependem das qualidades físicas e das mudanças que as gerações humanas lhe atribuem (HOLZER, 1997).

O rio fazia parte do quintal da casa, fornecia alimento, era a via de transporte, principal fonte de lazer e de renda sazonal para os moradores. Esse bem natural, o rio, não poderia reconstruir em outro lugar por nenhum arquiteto. A memória e as boas lembranças do rio permaneceram vivas nas mentes de todos os que vivem, hoje, momento de dúvida e incerteza referente ao futuro da comunidade.

No Gráfico 02 podem-se notar as atividades antes realizadas pelos moradores e que, agora, não mais fazem parte da rotina dos comunitários, caindo no esquecimento. Segundo Santos (1999, p. 65), “o sentimento de pertencimento a um determinado lugar constrói uma introspecção de valores que condiciona o modo de vida dos indivíduos". 
|Darlene Costa Silva | Maria Madalena de Aguiar Cavalcante |

Gráfico 02 - Perda de hábitos

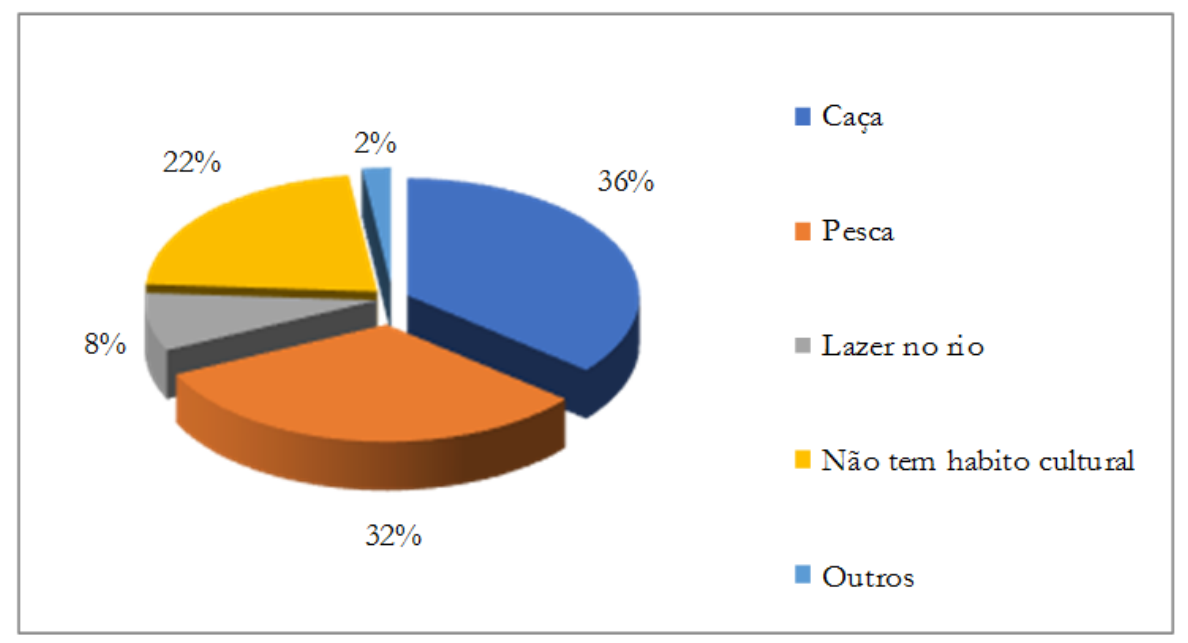

Fonte: Levantamento de campo, 2019.

No que concerne à relação entre os produtores rurais e o lugar em que vivem, Alves (2004, p. 204) menciona que a escala da comunidade permite entender os elos de sociabilidade entre os moradores. "O lugar é tido como a base da vida cotidiana e da sociabilidade entre as pessoas". O sentimento de pertencimento ao lugar está relacionado ao trabalho, às formas de solidariedade, às atividades lúdico-religiosas, às relações de parentesco e vizinhança e à perspectiva dos filhos em continuar na propriedade e na agricultura.

Parte-se, assim, do princípio de que todo espaço ou lugar possui uma significação de existência que o torna singular, definidor de uma identidade que vem constituir pertencimento pelas práticas exercidas no cotidiano da comunidade de modo a consolidar uma referência para o lugar.

$\mathrm{Na}$ construção da Hidrelétrica Belo Monte iniciam-se novas relações que irão propiciar as condições de reprodução e permanência nos novos lugares. Entretanto, constata-se que, contraditoriamente, apesar da transformação, há uma resistência em permanecer nas margens do rio Xingu onde metade da sua propriedade passou pelo processo de inundação com o enchimento do lago da hidrelétrica. Os moradores que insistiram em permanecer na metade do lote que não foi indenizada tiveram que construir sua nova moradia nos fundos da propriedade com acesso à estrada.

Em 2015, das doze famílias que viviam no núcleo das margens do rio, com a construção da hidrelétrica e os conflitos estabelecidos entre os proprietários e o Consórcio no processo de indenizatório, as quais receberam somente pela cota de alagamento prevista pelos documentos oficiais do empreendedor, quatro famílias abandonaram a propriedade e oito permaneceram, removendo suas moradias a oitocentos metros da margem do rio. 
| Hidrelétrica Belo Monte: estudo da desterritorialização das famílias da Comunidade Babaquara Altamira/PA|

|Darlene Costa Silva | Maria Madalena de Aguiar Cavalcante |

O que consta no Projeto de Recomposição das Atividades Produtivas de Áreas Remanescentes é garantir às populações que permanecerão nas áreas remanescentes dos imóveis atingidos condições de produção e garantia de sustento sub-bases economicamente viáveis socialmente justas e ambientalmente saudáveis (PBA, p. 145/146, volume II).

Conforme a análise de área Remanescente conferida pela CNEC Worley Parsons $n^{\circ}$ NM263-4.1.46-Nt-073 é viável, economicamente, a permanência do proprietário/ocupante na área remanescente do referido imóvel. De acordo com a Figura 5, a área é remanescente de uma propriedade indenizada. Dessa forma foi realizada para os outros dez lotes da margem do rio, com exceção de um que foi indenizado totalmente por ficar inserido numa área alargada.

Figura 5 - Área remanescente indenizada

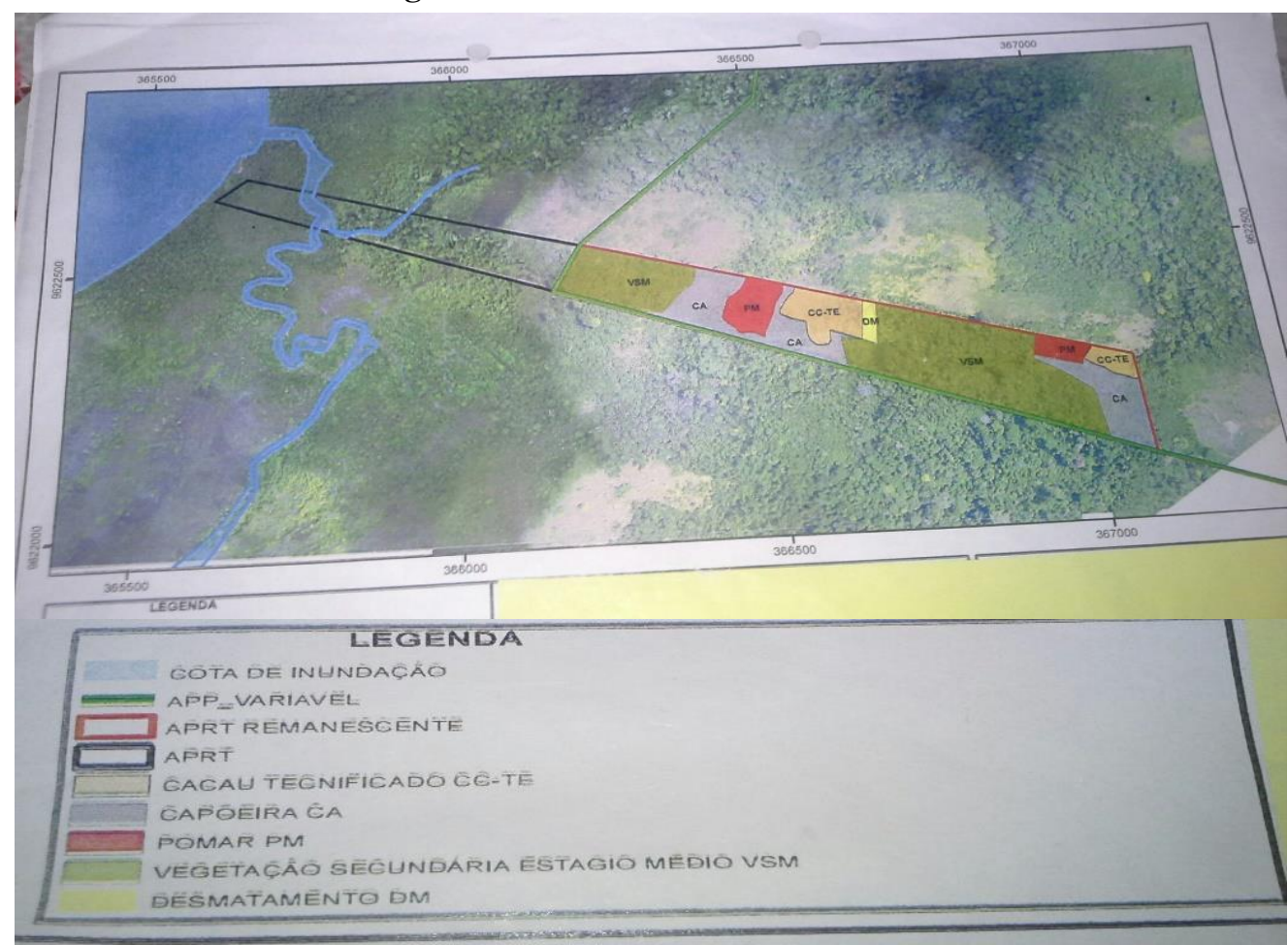

Fonte: Silva, 2016.

$\mathrm{Na}$ comunidade Babaquara há muito mais que apenas uma unidade produtiva; há relações e inter-relações construídas durante décadas, culturas enraizadas há muitas gerações. Com o enchimento do reservatório mudou-se a sua realidade, os seus vínculos sociais e a sua forma de viver: "Muitas são as memórias e as histórias para a população que verá parte da sua propriedade debaixo d'água para sempre” (SILVA, 2018, p. 121-122).

A concretização das indenizações e os oito moradores restantes, dos doze que viviam à margem direta do rio Xingu, vão tentando retomar suas atividades que antes já realizavam, sendo que os que resolveram ficar tiverem que mudar o local da residência em 
| Hidrelétrica Belo Monte: estudo da desterritorialização das famílias da Comunidade Babaquara Altamira/PA|

\section{|Darlene Costa Silva | Maria Madalena de Aguiar Cavalcante |}

torno de mil metros distante das margens. Mas aos poucos começam a reviver a rotina que tinham antes isso e fica bem visível no comentário do morador que revela o seu cotidiano na sua propriedade:

\footnotetext{
Voltei a plantar a minha roça, coisa que fazia antes com todo prazer. Estou plantando milho, macaxeira, feijão, mais cacau, criando de novo galinha, já penso em trazer porco, o ruim é porque aqui ainda não tem energia e nem estrada do centro para cá, porque com essa história de barragem perdemos foi o nosso benefício, porque se ia alagar tudo não teria motivo para melhorar nada. Agora estou aqui praticamente sozinho; os vizinhos mais próximos todos abandonaram os lotes e com isso nem sei se vou ter direito a receber energia, me sinto abandonado. Só sei que já voltei a produzir um pouquinho de farinha para despesa. E estamos aqui e seja o que Deus quiser (Entrevistado 5, 2016).
}

Das oito famílias restantes, quatro estão sendo afetadas duplamente pela hidrelétrica, pelo fato de que tinham casa na cidade exatamente nos bairros onde os moradores foram realocados para os novos Reassentamentos Urbanos Coletivos (RUCs).

Nestes termos, vem sendo considerado que o efeito da mudança de sua moradia a cerca de 800 metros distantes da margem do rio, que corresponde ao que foi indenizado pelo consórcio construtor, gera a refuncionalização da comunidade, acoplando com a retirada da determinação de que os moradores parassem de fazer suas roças. As lógicas externas afetaram diretamente a comunidade e seu modo de vida.

A construção da hidrelétrica impactou fortemente os pequenos agricultores existentes na sua Área de Influência Direta, levando a sua desestruturação econômica, cultural e ambiental. Os valores das indenizações foram considerados irrisórios, no sentido de que o valor esteja abaixo do necessário para adquirir outro imóvel, isto em decorrência da valorização econômica e imobiliária que ocorreu na cidade. No que tange às terras rurais produtivas, perdendo-se essas áreas as pessoas perderam suas fontes de renda e sustento, o que não pode ser suprido por uma indenização desapropriatória.

De acordo com o RIMA (2009), “as medidas propostas para os impactos gerados pela aquisição de imóveis rurais e perda de atividades produtivas estão, na maioria, no Plano de Atendimento à População Atingida", com diferentes programas que ficarão a cargo da concessionária da obra, objetivando a diminuição dos impactos causados às comunidades que vivem de economia familiar (RIMA, 2009, p. 92). Significativas transformações ocorrem no uso da terra, nos modos de produção e nas relações de trabalho.

A base produtiva foi alterada e se desenvolveu atividade agrícola limitada e especializada para o suprimento do mercado, como é o caso do cacau. Segundo o PBA 
| Hidrelétrica Belo Monte: estudo da desterritorialização das famílias da Comunidade Babaquara Altamira/PA|

|Darlene Costa Silva | Maria Madalena de Aguiar Cavalcante |

(2011, p. 174), considera-se importante e necessário efetuar um estudo minucioso sobre a cadeia produtiva do cacau na área de influência direta da Hidrelétrica de Belo Monte.

As populações atingidas pelos grandes empreendimentos do setor hidrelétrico não são feitas de maneira a preservar suas práticas culturais. Ao contrário, os empreendedores têm optado por indenizações individuais, em detrimento do remanejamento coletivo para locais que permitam aos grupos atingidos reproduzir suas vidas nos mesmos moldes anteriores, com a manutenção de seus laços sociais, de seus modos de sobrevivência e de seus valores culturais.

Em relação ao transporte da produção e produtos extrativistas, a locomoção era realizada em animais ou, muitas vezes, nas próprias costas, via picadas abertas na floresta até a beira do rio, onde ainda sofriam com as irregularidades dos barcos, que notadamente expressam a insegurança e o desconforto ao navegar, principalmente por conciliar nas viagens o transporte de produtos e pessoas (SILVA, 2013).

Quando se pensa em Belo Monte, é impossível não se lembrar dos vários conflitos para inviabilizar o empreendimento, diante das inúmeras falhas de projetos que, hoje, já são visíveis. Um deles que foi discutido dizia respeito que o rio Xingu não iria comportar um projeto desses, por não ter vazão, mas o que vemos hoje é o sobe e desce do nível do rio Xingu, que perde seu volume muito rápido em sua margem e demora a encher. O volume de água que abastece o reservatório é controlado pelo vertedouro principal, que fica na barragem Pimental.

\section{CONSIDERAÇÕES FINAIS}

A partir do exposto, buscou-se analisar as transformações ocorridas no espaço agrário da Comunidade Babaquara, a partir da intensificação das relações capitalistas de produção, bem como os resultados nas atividades realizadas pelos agricultores e sua trajetória até se fixar nesse lugar. No processo, a comunidade se tornou espaço para a realização ampliada do capital, de formas diferenciadas e de caracterização de diferentes sujeitos sociais do espaço.

Em Babaquara, com a construção da hidrelétrica Belo Monte foi perceptível à perda do sentimento de pertencimento e a transformação nos meios e modos de vida da população local; moradores que não tiveram suas demandas alcançadas e que forçosamente se readaptaram a um novo território. A acessibilidade da Comunidade Babaquara antes da construção da hidrelétrica se dava tanto pelo rio como pela estrada, agora, a relação dos 
| Hidrelétrica Belo Monte: estudo da desterritorialização das famílias da Comunidade Babaquara Altamira/PA|

|Darlene Costa Silva | Maria Madalena de Aguiar Cavalcante |

moradores com a dinâmica do rio acabou, pois o acesso é feito apenas pela estrada denominada Transassurini.

A população afetada permite situar o seu território como uma sucessão de paisagens, que retratam os distintos momentos de sua história. Ao contrário dos territórios ocupados por sociedades modernas, em que os elementos de paisagens passadas são rapidamente suprimidos, atualizados ou ressignificados, o território das comunidades ribeirinhas mantém vivos e atuantes muitos dos elementos que contribuíram para a formação histórica da região.

A implantação de um grande empreendimento, como o caso da Usina Belo Monte, significa um verdadeiro retrocesso quando se tem em mente a perda de laços sociais concretos e subjetivos que foram sendo construídos ao longo dos anos por estas populações. De fato, existem bens materiais e imateriais que representam valores simbólicos que dinheiro nenhum pagará. Como por exemplo, as festas religiosas e culturais.

Os laços de parentesco, compadrio e amizade foram fragmentados, distanciados e enfraquecidos pelo processo de desterritorialização. O exemplo mais forte e lamentado pela maioria dos entrevistados foi a perda da estreita e cotidiana relação com o Rio Xingu.

O rio faz parte do quintal da casa, fornece alimento, é a via de transporte, principal fonte de lazer e de renda sazonal para os ribeirinhos da região. Esse bem natural não poderia reconstruir em outro lugar por nenhum arquiteto. A memória e as boas lembranças do rio permanecem vivas nas mentes de todos.

A construção da Barragem de Belo Monte representa a edificação de uma catedral tecnológica, sob a qual submergiram um grande acervo de elementos materiais e imateriais que produziram, na região, um determinado modo de vida e de expressão simbólica das populações que sucessivamente a habitaram. Aqui, é importante destacar que parte destas expressões materiais e simbólicas se encontra num processo de ressignificação dentro das novas perspectivas dos moradores.

Estima-se que os resultados deste estudo possam lançar novas luzes nos debates, principalmente, em posições que questionem as ações necessárias de preservação da memória dessas populações, que, em muitas circunstâncias, situa a essência de suas vidas.

\section{REFERÊNCIAS}

ALVES, José. A dinâmica agrária do município de Ortigueira (PR) e a reprodução social dos produtores familiares: uma análise das Comunidades Rurais de Pinhalzinho e Vila Rica. 2004. 316 f. Dissertação (Mestrado em Geografia) - Faculdade de Ciências e Tecnologia, Universidade Estadual Paulista, Presidente Prudente, 2004. 
|Darlene Costa Silva | Maria Madalena de Aguiar Cavalcante |

ELETROBRAS. Aproveitamento Hidrelétrico Belo Monte: Relatório de Impacto Ambiental - Rima. Rio de Janeiro: Eletrobrás, 2009.

EIA/RIMA. LEME Engenharia. Relatório de Impacto Ambiental - Rima, Estudo de Impacto Ambiental: Aproveitamento hidrelétrico Belo Monte. Brasília: Ministério de Minas e Energia, Eletrobrás, maio 2009.

EIA - Estudo de Impacto Ambiental. Aproveitamento Hidrelétrico Belo Monte. Diagnóstico da Área Diretamente Afetada/ADA. Meio Socioeconômico e Cultural - ADA rural. Leme Engenharia Ltda, Brasília, dez. 2009. Volume 24, p. 529.

GUATTARI, Félix; RONILK, Suely. Micropolítica: cartografias do desejo. 10. ed. Rio de Janeiro: Vozes, 2010.

HAESBAERT, Rogério. O mito da desterritorialização: do "fim dos territórios" à multiterritorialidade. 4. ed. Rio de Janeiro: Bertrand Brasil, 2009.

HAESBAERT, Rogério; BRUCE, Glauco. Desterritorialização: entre as redes e os aglomerados de exclusão. In: CASTRO, I. E.; GOMES, P. C.; CORRÊA, R. L. (Org.). Geografia: conceitos e temas. Rio de Janeiro: Bertrand Brasil, 2003. p. 166-205.

HAESBAERT, Rogério; BRUCE, Glauco. A desterritorialização na obra de Deleuze e Guattari. Revista GEOgraphia, Niterói, ano IV, n. 7, p. 7-31, 2002.

HOLZER, Werther. Uma discussão fenomenológica sobre os conceitos de paisagem e lugar, território e meio ambiente. Território, LAGET/UFRJ, v. 2, n. 3, p. 77-85, jul./dez. 1997.

NORTE ENERgiA S.A. (NESA). Plano Básico Ambiental - Volume II: Plano de Atendimento à População Atingida. Brasília: NESA, 2011.

RIMA - RELATÓRIO DE IMPACTO AMBIENTAL. Aproveitamento Hidrelétrico Belo Monte. Brasília, 2009.

SAQUET, Marcos Aurélio. Abordagens e concepções de território. 2. ed. São Paulo: Expressão Popular, 2010.

SANTOS, Milton. Metamorfoses do espaço habitado. 3. ed. São Paulo: Hucitec, 1994.

SILVA, Darlene Costa da. As transformações no espaço agrário da comunidade Babaquara, município de Altamira - Pará. 2013. Monografia (Graduação em Geografia) - Faculdade de Geografia, Universidade Federal do Pará, Altamira, 2013.

SILVA, Darlene Costa da. Uma interpretação geográfica dos impactos da hidrelétrica Belo Monte: estudo de caso da Vila Santo Antônio e da Comunidade Babaquara na microrregião de Altamira-PA. 2018. 153 f. Dissertação (Mestrado em Geografia) - Instituto de Filosofia e Ciências Humanas, Universidade Federal do Pará, Belém, 2018.

SUZUKI, Júlio César. De povoado à cidade: a transição do rural ao urbano em Rondonópolis. 1996. Dissertação (Mestrado em Geografia Humana) - Faculdade de Filosofia, Letras e Ciências Humanas, Universidade de São Paulo, São Paulo, 1996. 
| Hidrelétrica Belo Monte: estudo da desterritorialização das famílias da Comunidade Babaquara Altamira/PA|

|Darlene Costa Silva | Maria Madalena de Aguiar Cavalcante |

TEDESCO, João Carlos. Terra, trabalho e família: racionalidade produtiva e ethos camponês. Passo Fundo: EDIUPF, 1999. 